large amount of electric power may disorganise many factories. In the usual design of high pressure insulators, cement is used inside the porcelain to join the shells and the metal parts together. Any expansion of the cement imposes bursting stresses on the porcelain, which often cracks. Some manufacturers, with this danger in view, sacrifice some of the mechanical strength of the joint by inserting elastic layers of bitumastic paint and, in addition, dilute the cement with sand to reduce the percentage expansion. Continental engineers have recently been using insulators in which internal cement layers have been entirely eliminated. They consist of porcelain cylinders carrying suitable projections called rainsheds and containing no cement layers. The elasticity of the flanges takes up the expansion of the cement. This cylindrical construction has been developed in Great Britain by Messrs. Steatite and Porcelain Products, Ltd., who export them abroad. They now supply $132 \mathrm{kv}$. cylindrical type switchgear insulators for the substations of the latest section of the British grid. The disadvantage of the wide base customary with this type of insulator has been overcome by the introduction of an ingenious series of flanged castings, so made that all the standard methods of fixing now in use can be applied to the cylindrical insulators. They are so designed that the greatest possible amount of surface is exposed to natural cleaning. The use of these new insulators on the grid will, during the next few years, give an opportunity of comparing them with the older type under working conditions. Their increasing use on lower voltages should help towards the electrician's ideal of complete continuity of service.

\section{Boiler Plant in Power Stations}

To the electrical engineer a knowledge of the thermal efficiency, operating costs, and trustworthiness of the boiler plant in his power station is almost as important as a knowledge of his electrical machines. J. Bruce read a lengthy paper on this subject on March 10 to the Institution of Electrical Engineers. $\mathrm{He}$ had, however, to omit the discussion of flue gas, dust, and sulphurous fume extraction, as the Chimney Emissions Committee has not yet reported. $\mathrm{He}$ pointed out that a study of present-day American conditions leads to the general conclusion that the best American generating stations have a higher thermal efficiency than those representative of the best average British practice. A number of American generating stations produce a kilowatt hour for a heat expenditure of less than 14,000 B.Th.U. This is due to better boiler plant and to the higher grade of employee used in operating it. The Detroit Edison Company, for example, has a boiler-house efficiency of 87 per cent. In the United States, when a station uses high steam pressure, it either uses a pressure of about $600 \mathrm{lb}$. per square inch or one of about $1300 \mathrm{lb}$. per square inch. At the present time, there are 15 boiler units operating successfully and with no serious troubles in the neighbourhood of the higher pressure. Large boiler units capable of evaporating one million pounds of water per hour are being successfully operated. The capital cost of the boiler plant required increases rapidly with the pressure when it is above $600 \mathrm{lb}$. per square inch. Consequently, when coal is cheap the interest on the increased capital cost may more than offset the gain in the heat efficiency. America has the advantage over Great Britain that combustion equipment can be developed for a particular quality of coal owing to the geological characteristics of the coal being uniform over wide areas. British practice, although not obtaining such excellent thermal results, has yet made good progress of recent years.

\section{Manufacture of Electric Lamps}

ONe of the exhibits at the Faraday Centenary Exhibition last September which attracted much attention was that showing some of the operations in the manufacture of electric lamps. Only a few of the operations could be demonstrated, but much further information on the subject is contained in an article on "The Mass Production of Electric Incandescent Lamps" in Engineering for March 25. The article contains a description of the new Wembley Lamp Factory of the General Electric Co., Ltd., which has a capacity of 25,000,000 lamps a year. All the machines used are illustrated, and many interesting facts are given about the manufacture of the components of a lamp. The tungsten for the filament is obtained from the ore scheelite. It is first prepared in the form of powder, which is subjected to very great pressure and then treated in an atmosphere of hydrogen, first at about $1200^{\circ} \mathrm{C}$., and then at about $3000^{\circ} \mathrm{C}$. Sixty drawings are required to reduce the original $1 \mathrm{~mm}$. rod to a filament $0.015 \mathrm{~mm}$. in diameter, and a tungsten bar $\frac{1}{4}$ in. square and 10 in. long can be drawn into 15 miles of filament. The leading-in wires, which used to be of platinum, are now of coppercovered nickel-steel. The important operation of exhausting the lamps and then filling them with gas is done on capstan machines, each holding twentyfour lamps. Vacuum pumps reduce the pressure in them to a few thousandths of a millimetre of mercury, heat from an oven drives off moisture and adsorbed gas, and, while still hot, the lamps are filled with a mixture of nitrogen and argon, the internal pressure when cold being about two-thirds of an atmosphere.

\section{The World's Natural History Societies}

THE diffusion of scientific interests in the world, as indicated by the numbers and distribution of natural history societies, has been studied by Enrique Sparn (Bol. Acad. Nac. Ciénc. Buenos Aires, vol. 31, p. 171; 1931). Confining the inquiry to the larger societies, with a membership of 500 or more, the author finds that the world total amounts to 116 societies, of which 52 are devoted to natural history in general, 34 to zoology, 14 to botany, and 16 to geology. From a geographical point of view, natural history interests would appear to be tolerably restricted, for when we have mentioned 83 European societies with a total membership of 132,182 individuals, and 30 American societies with a membership of 160,947 , there remain only 2 societies in Asia with a membership of 1938,

No. 3260, Vou. 129] 